\title{
Reproduksi Budaya dalam Pentas \\ Kesenian Tradisional di Balai \\ Soedjatmoko
}

Jurnal Analisa Sosiologi

April 2017, 6(1): 42-54

\section{Rosyid Nukha ${ }^{1}$}

\begin{abstract}
The aim of this research is to know about the culture reproduction process that happen ang to know the actor on the traditional art perfromances in Soedjatmoko Hall. This is a qualitative research with case study as its approach. The data collection done by interview, participatory observation ang documentation. The primary data collected by indepth interview and participatory observation. That data being analyzed using interactive model. The data validity done by source triangulation. the art performance reproduction is being analyzed by Pierre Bourdieu's theory. The research found that the actors in the culture reproduction on traditional art performances include keroncong art groups, kararwitan art groups, macapat art groups and Soedjatmoko Hall. Those actor have cultural capital, social capital, symbolic capital and economic capital that supported the reproduction process. Culture reproduction in the traditional art through Keroncong Bale, Macapat Soedjatmakan, dan Klenengan Selasa Legen art performance by perform again the traditonal art. Reproduction process happen through the use of pakem and the use of symbol, the delivery of meaning in the art performance, performance's procedures, the songs and the materials is adjusted to the pakem.
\end{abstract}

Keywords: Soedjatmoko Hall, Culture Reproduction, Art Performance.

\footnotetext{
${ }^{1}$ Program Studi Magister Sosiologi Universitas Sebelas Maret Email: rosyidnkha.mail@gmail.com
} 


\begin{abstract}
Abstrak
Penelitian ini bertujuan untuk mengetahui proses reproduksi budaya yang terjadi dan mengetahui aktor yang terlibat dalam pementasan kesenian tradisional di Balai Soedjatmoko. Jenis penelitian ini adalah kualitatif dengan strategi studi kasus. Pengumpulan data dilakukan dengan wawancara, observasi partisipatif, dan dokumentasi. Data primer dikumpulkan melalui wawancara mendalam dan observasi partisipatif. Analisis data menggunakan model interaktif. Validitas data menggunakan reviu informan dan trianggulasi sumber. Reproduksi kesenian tradisional di Balai Soedjatmoko dikaji dengan pemikiran Pierre Bourdieu. Hasil penelitian menunjukkan Aktor-aktor yang terlibat dalam reproduksi budaya pada pementasan kesenian tradisional meliputi kelompok kesenian keroncong, kelompok kesenian karawitan, kelompok kesenian macapat, dan Balai Soedjatmoko. Aktor kesenian tradisional tersebut memiliki modal budaya, modal sosial, modal simbolik, dan modal ekonomi yang mendukung proses reproduksi. Reproduksi budaya dalam kesenian tradisional melalui penyelenggaraan pentas kesenian Keroncong Bale, Macapat Soedjatmakan, dan Klenengan Selasa Legen dengan mementaskan kembali kesenian tradisional yang sudah berkembang. Proses reproduksi yang terjadi melalui penggunaan pakem yang baku serta penggunaan simbol, penyampaian makna dalam pementasan kesenian, tata cara pementasan, lagu yang dibawakan dan materi yang dipilih dilestarikan sesuai dengan pakemnya.
\end{abstract}

Kata Kunci: Balai Soedjatmoko, Reproduksi Budaya, Kesenian Tradisional. 


\section{PENDAHULUAN}

Studi tentang reproduksi budaya telah banyak dilakukan oleh peneliti lain pada bidang ilmu ilmu sosial (Lyons (2001); Well (2006), Shohibuddin (2003), Yusuf (2012)). Obyek kajian yang berfokus pada dinamika sosial komunitas tertentu. Pembahasan reproduksi budaya selalu dikaitkan dengan proses pemaknaan struktur sosial di masyarakat. Bourdieu mengatakan dalam proses sosial akan disertai reproduksi sosial yang secara otomatis proses reproduksi budaya akan menyertainya. Reproduksi budaya diartikan sebagai pelestarian nilai nilai budaya dari satu generasi ke generasi lain.

Artikel ini memaparkan hasil penelitian serupa yang fokus pada reproduksi budaya. Penelitian ini mengkaji pada aspek reproduksi budaya pada pementasan kesenian tradisional di Balai Soedjatmoko Surakarta. Tujuan dari kajian ini untuk mengetahui proses reproduksi budaya yang terjadi dan mengetahui aktor yang terlibat dalam pementasan kesenian tradisional di Balai Soedjatmoko Surakarta. Kota Surakarta merupakan kota yang terbentuk atas sisa kejayaan Kerajaan Mataram. Sejak awal, produksi kebudayaan sudah menjadi tonggak awal berdirinya kota dengan titik penting yang sangat berperan sebagai pusat kebudayaan yaitu Keraton Kasunanan dan Keraton Mangkunegaran. Beragam hasil kebudayaan tersebut mulai dari upacara adat, kesenian, artefak, sistem sosial menjadi bagian kehidupan masyarakat yang kental dalam setiap praktik kehidupan. Semenjak masa Kerajaan Majapahit sampai dengan Kerajaan Mataram (abad 13-18) atau pada masa prakolonial Keraton yang menjadi pusat pemerintahan sekaligus menjadi pusat kebudayaan. Praktis ritual kebudayaan didominasi dan diproduksi oleh Keraton. Salah satu arena berlangsungnya praktek kebudayaan tersebut adalah alun-alun. Keberadaan alun-alun sebagai bagian dari keraton mempunyai peranan yang sangat penting yaitu sebagai ruang publik, lambang kekuasaan raja, tempat diselenggarakannya upacara adat, ritual kebudayaan, dan tempat pertunjukkan kekuasaan militer yang profan (Santoso,1984). Kota sebagai wajah peradaban dunia dan arena lokomotif modernisasi terus mengalami perubahan dan terkonstruksi berbagai konsepsi baru mengenai kota. Kota Solo sebagai salah satu potret kota tua di Indonesia turut mengalami 
perubahan baik fisik, sosial, ekonomi maupun kultural. Perubahan tersebut tampak dalam program pembangunan pemerintah kota dengan mendayagunakan potensi daerah melalui kebijakan otonomi daerah atau desentralisasi seperti yang tertuang dalam UU no.32 tahun 2004.

Semenjak diluncurkan branding Solo the Spirit of Java pada era kepemimpinan walikota Jokowi, Kota Solo dipenuhi agenda kebudayaan kota setiap tahunnya sebagai sebuah wisata budaya untuk menarik wisatawan dari luar. Even-even besar menjadi seperti Solo International Ethnic Music (SIEM), Solo International Performing Arts (SIPA), Solo Batik Carnival (SBC), Festival Jenang, Solo Keroncong Festival menjadi andalan sampai dengan sekarang. Kemeriahan kirab yang selalu diadakan untuk menyambut peringatan hari kemerdekaan, atau even tertentu menjadi ciri khas pemerintah kota, jadi motif untuk mengkonstruksi kota Solo sebagai kota wisata budaya.

Praktik-praktik kebudayaan tersebut kemudian mendominasi penyelenggaraan agenda kebudayaan dengan kepentingan pariwisata. Identitas dengan kepentingan pariwisata yang sudah melekat tersebut menyebabkan identitas budaya kota yang kental dengan tradisi perlahan akan mati pada lapisan masyarakat bawah. Roh kehidupan kebudayaan Jawa yang seharusnya dilestarikan akan mengalami kemandegan. Ditengah gencarnya modernitas yang melanda di kota sebagai arenanya, budaya pop turut mendominasi kebudayaan kota. Anthony Giddens menyatakan bahwa perombakan-perombakan yang dilakukan sistem raksasa globalisasi bergerak atas semangat ideologi positivisme berdasar akal, kebenaran empiris, universalitas, dan alasan-alasan kemajuan yang sangat memihak pada kepentingan aktivitas materiil. Semua aktivitas kemudian dipahami berjalan apa adanya, bahkan tanpa tujuan, manfaat, praktis, dan dehumanis (Giddens, 2001: 15).

Dalam kondisi globalisasi budaya saat ini proses produksi kultural berupa kesenian sampai dengan kesusastraan berpusat dalam kelompokkelompok kolektif masyarakat dan komunitas, setelah Keraton berangsurangsur kehilangan hegemoninya. Walaupun terdapat lembaga pendidikan seni Institut Seni Indonesia (ISI) Surakarta namun lembaga tersebut terbatas hanya pada kalangan tertentu yang dapat mengaksesnya. Pertunjukkan seni 
di Taman Budaya Jawa Tengah pun seperti hanya menjadi showroombagi para seniman yang lahir dari lembaga pendidikan seni tersebut. Di kampung-kampung banyak dijumpai kelompok keroncong kampung, kelompok macapat, atau kelompok karawitan yang berkesenian hanya untuk menyalurkan ekspresi anggotanya saja. Berbagai arena produksi kultural tersebut tersebar diberbagai ruang-ruang publik Kota Solo, salah satunya Balai Soedjatmoko. Penelitian ini dilakukan berfokus pada praktek pementasan kesenian tradisional di Balai Soedjatmoko Surakarta. Dalam pementasan kesenian tradisional tersebut terjadi proses reproduksi budaya.

Reproduksi budaya terjadi dalam proses transmisi budaya dalam kehidupan sehari hari. Sehingga kebudayaan secara turun temurun akan terus berproses seperti yang dibayangkan Clifford Gertz bahwa kebudayaan merupakan pola dari makna-makna yang terjalin secara menyeluruh dalam simbol-simbol yang ditransmisikan secara historis (Geertz,1973:89). Praktik-praktik kebudayaan akan senantiasa mengalami proses reproduksi, rekonstruski, bahkan komodifikasi atas resiko bergulirnya modernitas. Hasil akhir dari proses transmisi tersebut tergantung dari aktor dalam arena kebudayaan itu.

Beberapa kajian yang telah dilakukan berfokus pada reproduksi budaya diantaranya yang dilakukan Lyons (2001) mengkaji perubahan narasi ketika ditransmisikan antara beberapa individu dan berisi informasi yang relevan dengan stereotip budaya. Dikatakan bahwa orang-orang yang mendukung reproduksi stereotip-stereotip konsisten atas informasi yang tidak konsisten dalam komunikasi, membuat narasi tersebut menjadi lebih stereotip dan semakin mempertahankan stereotip budaya. Sebuah narasi tentang seorang pemain sepak bola, yang menunjukkan perilaku stereotip relevan dengan pekerjaannya, ditularkan melalui 20 rantai komunikasi empat orang. Informasi stereotipsecara konsisten direproduksi lebih dari informasi stereotip yang tidak konsisten, yang terakhir semakin disaring dari cerita selama satu rantai. Selain itu, ketika isi cerita dibandingkan seluruh satu rantai, perbedaan ditemukan ketika cerita itu awalnya dikirim namun pemusatan terhadap isi cerita serupa muncul melalui penularan kolektif. Temuan ini dibahas sehubungan dengan pemeliharaan stereotip budaya dan reproduksi budaya melalui kegiatan individu dalam jaringan sosial. 
Muhammad Yusuf (2012) mengkaji hubungan aspek historisitas dengan praktik berpolitik orang Bugis Wajo dalam berpolitik. Bangunan struktur masyarakat Wajo yang dipelajari dari rangkaian sejarah untuk menemukan aspek yakni status tradisional yang menjadi salah satu komponen dalam budaya politik dan setidaknya cukup mempengaruhi bagaimana praktik politik yang dilakukan orang Bugis Wajo. Hasil yang ditemukan adalah pada proses konstruksi dan mempertahankan kekuasaan sebagai bagian dari warisan (sejarah) budaya, dimensi status kemudian direproduksi sedemikian rupa oleh kelompok masyarakat keturunan Arung. Pada kadar tertentu reproduksi status cukup mempengaruhi kultur masyarakat Wajo dalam menduduki kekuasaan dan dihadirkan pada praktikptaktik politik sebagai bagian dari upaya strategi politik mendominasi kekuasaan.

\section{METODE PENELITIAN}

Penelitian yang dilakukan menggunakan metode kualitatif dengan strategi penelitian studi kasus. Studi kasus sebagai suatu strategi penelitian adalah suatu inkuiri empiris yang menyelidiki fenomena didalam konteks kehidupan nyata bila batas-batas antara fenomena dan konteks tak tampak dengan tegas dan dimana multi sumber buku dimanfaatkan (Yin, 1997: 18). Menurut Robert K Yin, melalui studi kasus akan lebih banyak berkutat pada atau berupaya menjawab pertanyaan-pertanyaan bagaimana dan mengapa, serta pada tingkat tertentu juga menjawab pertanyaan apa/apakah dalam kegiatan penelitian. Menentukan tipe pertanyaan penelitian merupakan tahap yang sangat penting dalam penelitian terutama memahami bahwa setiap pertanyaan mengandung substansi dan bentuknya (Bungin,2005:21).

Pendekatan studi kasus digunakan untuk mengetahui keunikan proses reproduksi budaya dalam pementasan kesenian tradisional di Balai Soedjatmoko. Tujuannya untuk mendeskripsikan pentas kesenian di Balai Soedjatmoko dengan spesifik tanpa dapat digeneralisir untuk menjelaskan even serupa yang ada ditempat lain. Kota Solo sebagai kota seni budaya memiliki banyak arena seni kebudayaan seperti Taman Budaya Jawa Tengah, Gedung Wayang Orang, Taman Balekambang, Taman Sriwedari, 
Gedung Kesenian Solo dan Ngarsopuro. Reproduksi budaya dalam kesenian tradisional di Balai Soedjatmoko dikaji sebagai sebuah realitas kontemporer dan bersifat kompleks dalam konteks kehidupan seni dan budaya di Kota Solo. Maka studi realitas ini sebagai sebuah kasus dapat dibedakan sebagai kasus tunggal. Dengan menelisik aktor-aktor, faktor serta proses terlaksananya pentas di Balai Soedjatmoko ini maka dapat dideskripsikan tindakan-tindakan dari aktor tersebut yang mereproduksi budaya dalam pementasan kesenian tradisional tersebut.

Analisa data dilakukan dengan melakukan beberapa tahap yaitu melalui tiga alur kegiatan yaitu reduksi data, penyajian data, dan penarikan kesimpulan (Slamet, 2006:140). Setelah tiga langkah tersebut sudah dilakukan kemudian analisa data dengan model interaktif dilakukan dengan cara melakukan penarikan simpulan dan verifikasi atas semua hal yang terdapat dalam reduksi dan sajian datanya ketika pengumpulan data berakhir.

\section{HASIL DAN PEMBAHASAN}

Salah satu ranah kesenian dan kesusastraan di kota Solo adalah Balai Soedjatmoko. Sebagai arena seni yang otonom Balai Soedjatmoko mempunyai konsentrasi terhadap batasan arenanya dengan arena seni yang lain. Salah satunya, arena kesenian tradisional yang mereka bangun berdasarkan seni yang mempunyai akar tradisi kuat di Kota Solo. Meliputi kesenian Macapat, Karawitan, dan Keroncong. Di dalam ranah tersebut muncul kelompok kesenian dan seniman yang melakukan pentas kesenian tradisional. Melalui berbagai even kesenian tradisional seperti Keroncong Bale, Klenengan Selasa Legen, dan Macapat Soedjatmakan. Nilai-nilai simbolik pada kesenian tradisional tersebut dihadirkan kembali pada masyarakat luas melalui pementasan kembali kesenian keroncong, karawitan, dan macapat.

Balai Soedjatmoko menjadi arena bagi seniman dan kelompok kesenian dari berbagai kesenian bisa mengekspresikan ketrampilan mereka. Beragam agenda seni diadakan setiap bulannya dalam satu tahun. Seperti pameran lukisan, pameran desain grafis, pameran poster, diskusi novel, diskusi puisi, diskusi buku, pertunjukkan wayang, pentas musik jazz, pentas 
musik blues, workshop menulis, diskusi film dokumenter, pentas musik keroncong, pentas karawitan, dan macapat. Setiap pentas tersebut dikuratori oleh orang yang berkompeten dalam bidangnya dengan melibatkan seniman di Kota Solo. Even kesenian tradisional Keroncong Bale, Macapat Soedjatmakan dan Klenengan Selasa Legen merupakan pentas yang melibatkan berbagai kelompok yang diminta untuk tampil setiap pegelarannya.

Di Kota Solo ada empat jenis aktor dalam ranah kesenian tradisional yaitu pelaku budaya, pengembang budaya, pelestari budaya, dan kritikus budaya. Penyelenggaraan kesenian Keroncong Bale, Macapat Soedjatmakan, dan Klenengan Selasa Legen merupakan praktik budaya dalam salah satu komponen konsep kebudayaan yang dijelaskan oleh Raymond William, kebudayaan menyangkut tiga hal yaitu pertama mengenai perkembangan intelektual, spritual, dan estetik individu, kelompok atau masyarakat. Kedua menangkap sejumlah aktivitas intelektual atau artistik serta produk-produknya (film, kesenian, dan teater). Ketiga mengenai seluruh cara hidup, aktivitas, kepercayaan, dan kebiasaan masyarakat (Adeline dalam Sutrisno (Ed), 2005:258). Even kesenian tradisional di Balai Soedjatamoko sebagai praktik kesenian meliputi aktivitas intelektual artistik kelompok seniman keroncong, macapat, dan karawitan.

Habitus menghasilkan atau dihasilkan oleh dunia sosial (Ariyani, dkk., 2018). Pemikiran Bourdieu tentang konsep habitus sebagai salah satu faktor pendukung terjadinya proses reproduksi budaya dalam pementasan kesenian tradisional. Konsep ini sebagai upaya pemahaman dalam unsur reproduksi budaya yaitu ranah, praktik, dan agen/aktor. Secara tak langsung Bourdieu menyebutkan proses reproduksi budaya dalam pemikirannya tentang sistem pendidikan yaitu sebagai pemeliharaan pengetahuan dan pengalaman dari satu generasi ke generasi berikutnya. Bourdieu berpendapat bahwa kebudayaan kelompok dominanlah yang mengontrol sumber-sumber ekonomi, sosial, yang diwujudkan sekolah-sekolah, dan perwujudan inilah yang bekerja sebagai strategi reproduksi bagi kelompok dominan (Harker, 2009: 110). 
Penyelenggaraan pentass kesenian tradisional ini juga dimaksudkan untuk pemeliharaan pengetahuan dan pemahaman tentang kesenian tradisional (keroncong, macapat, dan karawitan) kepada masyarakat luas. Hal ini juga yang menjadi salah satu misi dari Balai Soedjatmoko untuk mengangkat kembali kesenian tradisional. Implementasi dari misi tersebut adalah menjalin kerja sama dengan beberapa kelompok seniman yang sebelumnya sudah aktif berkesenian, bersama-sama menyelenggarakan pentas kesenian keroncong, macapat dan karawitan. Penyelenggaraan kesenian tradisional di Balai Soedjatmoko sebagai praktik kebudayaan merupakan hasil hubungan dialektis antara struktur obyektif dengan fenomena subyektif. Hubungan ini kemudian dijelaskan melalui konsep habitus, ranah, dan modalyang menghasilkan praktik reproduksi budaya.

Para aktor yang terlibat dalam pelaksanaan even kesenian tersebut meliputi kelompok keroncong, kelompok karawitan dan kelompok macapatan. Mereka bekerja sama dengan pihak Balai Soedjatmoko yang dikelola oleh Bentara Budaya Solo. Sebelum terlibat dengan Balai Soedjatmoko para aktor tersebut sudah memiliki habitus domestik sendiri. Habitus tersebut terbentuk melalui proses sejarah selama dalam ranah kesenian yang digeluti para aktor. Seperti kelompok Swastika, sebagai grup keroncong kawakan memiliki anggota yang profesional dalam berkesenian. Hal ini merupakan bagian dari salah satu komponen habitus sebagai produk sejarah seperti yang dijelaskan Kleden, habitus pada waktu tertentu telah diciptakan sepanjang masa sejarah. Habitus yang termanifestasikan pada individu tertentu diperoleh dalam proses sejarah individu dan merupakan fungsi dari titik temu dalam sejarah sosial tempat ia terjadi (Kleden, 2005:361). Para aktor kesenian tradisional memiliki habitus kesenian dan komitmen bersama untuk melestarikan budaya dalam hal ini kesenian tradisional melalui reproduksi budaya dalam pentas kesenian tradisional.

Dalam praktik reproduksi budaya tersebut para aktor kesenian tradisional memiliki modal budaya, ekonomi, sosial, serta modal simbolik yang mencukupi untuk memperoleh akses tersendiri untuk memposisikan dirinya di Balai Soedjatmoko sebagai arena bagi aktor kesenian tradisional. Dalam proses reproduksi budaya tersebut modal menjadi konsep penting yang menunjang proses reproduksi. Bourdieu membagi modal tersebut 
menjadi empat macam, yaitu modal budaya, modal simbolik, modal sosial dan modal ekonomi. Modal merupakan logika yang mengatur perjuangan aktor dalam relasi kekuasaan di ranah (Harker Ed, 2009:16).

Modal yang dimiliki para aktor kesenian tradisional di Balai Soedjatmoko turut menentukan upaya reproduksi, menjadi faktor penunjang dan dapat pula menjadi penghambat upaya reproduksi. Pada kelompok Swastika modal budaya yang dimiliki berupa pendidikan kesenian yang melatarbelakangi mereka, sehingga menunjang pengetahuan pada kesenian keroncong. Pada kelompok Merdi Lambang modal budaya yang dimiliki berupa pendidikan seni yang menunjang pengetahuan pada kesenian macapat. Begitu pula pada kelompok Langen Suko, pendidikan seni yang melatar belakangi mereka menunjang praktik kesenian. Kemudian modal sosial yang dimiliki kelompok Swastika, Merdi Lambang dan Langen Suko berupa jaringan sosial yang mereka jalin bersamaan dengan pentas kesenian mereka. Serta solidaritas diantara mereka yang sangat kuat. Modal simbolik pada kelompok Swastika, Merdi Lambang dan Langen Suko berupa jam terbang pentas mereka. Semakin tinggi jam terbang penampilan yang dimiliki maka nama kelompok mereka akan lebih dikenal masyarakat. Dari ketiga kelompok tersebut hanya Swastika yang memiliki jam terbang paling tinggi dan sudah dikenal para pecinta keroncong di Kota Solo.

Dari sekian modal yang dimiliki aktor, modal budaya dan sosial mempunyai andil besar dalam mendukung reproduksi. Modal budaya yang dimiliki berupa pengetahuan seni dan budaya yang mencukupi. Modal sosial berupa jaringan sosial sudah terjalin dan dibangun kembali di ranah kesenian.Pihak yang terlibat dalam aktivitas kesenian ini melakukan perencanaan, pengorganisasian sebagai serangkaian proses reproduksi kesenian tradisional dengan pementasan sebagai pergerakannya. Mekanisme tersebut menjadi serangkaian proses reproduksi kesenian tradisional. Perencanaan meliputi rutinitas yang dilakukan kelompok kesenian. Kegiatan tersebut adalah latihan rutin yang diadakan setiap minggu. Pada kelompok keroncong Swastika mengadakan latihan rutin keroncong setiap hari rabu malam. Pada kelompok Merdi Lambang latihan rutin diadakan untuk mempersiapkan pementasan di Balai Soedjatmoko. Kemudian pada tahap pengorganisasian akan dilakukan pihak Balai Soedjatmoko yang 
berkoordinasi dengan kelompok kesenian yang akan tampil dalam pementasan Keroncong Bale, Macapat Soedjatmakan, dan Klenengan Selasa Legen. Agenda yang disusun akan dikurasi oleh kurator Balai Soedjatmoko kedalam periodesasi agenda kegiatan Balai Soedjatmoko. Tujuan dari kuratorisasi ini untuk menjaga pakem tertentu dari sebuah kesenian tradisional. Sehingga pelestarian nilai-nilai, simbol dan makna yang terkandung dalam kesenian tradisional tersebut terus terpelihara. Agenda yang telah dikuratori kemudian akan dipublikasikan meluas kepada masyarakat melalui media elektronik (handphone, radio), media jejaring sosial (web, facebook), media cetak (pamflet, leaflet).

Adanya berbagai even kesenian tradisional di Balai Soedjatmoko tersebut merupakan reproduksi budaya melalui pentas kesenian tradisional. Even Keroncong Bale, Klenengan Selasa Legen, dan Macapat Soedjatmakan adalah praktik kebudayaan yang digunakan sebagai alat untuk mereproduksi budaya. Reproduksi yang dilakukan berupa pementasan kembali kesenian tradisional yang dahulu pernah berkembang pesat. Seperti pada even Keroncong Bale, kelompok yang tampil memainkan lagu-lagu keroncong yang sudah populer, namun saat tertentu ada juga yang memainkan aransemen baru pada lagu yang sudah ada. Dalam pentas Macapat Soedjatmakan serat-serat kuno yang sudah jarang dipublikasikan, dibacakan kembali oleh kelompok macapat yang ditunjuk.Pementasan tersebut masih dengan membawakan pakem yang sejak awal digunakan.

Hal ini terlihat sekali dari pementasan kesenian macapat dalam even Macapat Soedjatmakan. Dimana setelah pembacaan serat-serat oleh pembaca, akan dijelaskan arti yang terkandung didalamnya kepada penonton. Isi dari serat-serat tersebut mengandung nilai-nilai sosial, moral, dan pendidikan. Hal ini yang saat ini jarang sekali ditemui pada pementasan kesenian yang lain. Lalu unsur persuasif ini berupa ajakan kepada masyarakat luas untuk ikut menghargai serta menjaga kesenian tradisional. Hal ini terlihat sekali pada pementasan kesenian keroncong dalam even Keroncong Bale. Penonton tak hanya dihibur dengan alunan musik keroncong tetapi juga diberikan kesempatan untuk turut serta naik ke atas panggung ikut berpartisipasi menyumbang lagu atau memainkan salah satu 
alat musik. Dengan begitu penonton tidak hanya diam saja sebagai penonton namun juga diajak secara langsung terlibat dalam upaya reproduksi ini.

\section{KESIMPULAN}

Bentuk reproduksi budaya dalam pementasan kesenian tradisional di Balai Soedjatmoko nampak pada even Keroncong Bale, Macapat Soedjatmakan, dan Klenengan Selasa Legen. Penggunaan pakem yang baku serta penggunaan simbol dan penyampaian makna dalam pementasan tersebut menjadi unsur yang terjadi dalam proses reproduksi budaya. Bagaimana tata cara pementasan, lagu yang dibawakan dan materi yang dipilih dilestarikan sesuai dengan pakemnya. Pementasan kesenian tradisional dikreasikan oleh Balai Soedjatmoko yang menjadi arena kesenian dan kesustraan di Solo. Proses kuratorial dilakukan sebagai bagian dari pemilihan kelompok kesenian dan menjaga konsep pelestarian kesenian tradisional. Aktor yang terlibat dalam kuratorial ini adalah seniman keroncong, seniman akademisi dan pegiat seni. Aktor tersebut didukung oleh habitus kesenian, modal budaya, modal sosial, dan modal simbolik yang dimiliki.

\section{UCAPAN TERIMA KASIH}

Terima kasih peneliti ucapkan kepada pihak-pihak yang telah membantu terlaksananya penelitian ini. Yaitu Balai Soedjatmoko, Keroncong Swastika, Karawitan Langen Suko, Macapatan Merdi Lambang, dan Dr. Argyo Demartoto yang telah membantu terlaksananya penelitian ini

\section{DAFTAR PUSTAKA}

Abdullah, Irwan. 2010. Konstruksi Dan Reproduksi Kebudayaan. Yogyakarta: Pustaka Pelajar

Anthony Lyons dan Yoshihisa Kashima. 2001. The Reproduction Of Culture: Communication Processes Tend to Maintain Cultural Stereotype. Jurnal Internasional Social Cognition Vol.19 Issue 3Bilton, Tony, 1996. Introductory Sociology (3rd ed). London: Macmillan

Ariyani, N. I., Demartoto, A., \& Zuber, A. (2018). Habitus Pengembangan Desa Wisata Kuwu: Studi Kasus Desa Wisata Kuwu Kecamatan Kradenan Kabupaten Grobogan. Jurnal Analisa Sosiologi, 4(2).

Bourdieu, Pierre. 2012. Arena Produksi Kultural Sebuah Kajian Sosiologi Budaya. Yogyakarta: Kreasi Wacana 
Bungin, Burhan,2005. Analisis Data Penelitian Kualitatif. Jakarta: Rajagrafindo Persada

Cresswell, John W.,1998. Qualitative Inquiry and Research Design:Choosing Among Five Traditions, USA: Sage Publications Inc

Edy Tri Sulistyo. 2005. Kaji Dini Pendidikan Seni. Surakarta: Lembaga Pengembangan Pendidikan UNS dan UNS Press.

Frits Van Well. 2006. Ethnicity,Youth Cultural Participation, And Cultural Reproduction In The Netherlands. Jurnal Internasional Poetics Vol.34 Issue 1

Giddens, Anthony. 2001. Runaway World: Bagaimana Globalisasi Merombak Kehidupan Kita. Jakarta: Gramedia Pustaka Utama

Hasan, Sandi Suwardi. 2010. Pengantar Cultural Studies. Yogyakarta: ArRuzz Media

Herdiansyah, Haris. 2010. Metodologi Penelitian Kualitatif. Jakarta: Salemba Humanika

Ibrahim, Idi Subandy (ed). 2004. Lifestyle Ecstasy. Yogyakarta: Jalasutra Jenks, Chris. 2013. Culture Studi Kebudayaan. Yogyakarta: Pustaka Pelajar

Jenkins, Richard. 2010. Membaca Pikiran Pierre Bourdieu. Yogyakarta: Kreasi Wacana

Kleden, Ignas. 2005. Habitus: Iman Dalam Perspektif Cultural Production dalam RP Andrianus Sunarko, OFM, dkk (eds). Jakarta: Sekretariat SAGKI

R.M. Sajid, 1984. “Babad Sala”. Surakarta: Reksopustoko

Ritzer, George dan Goodman, Douglas J. 2010. Teori Sosiologi. Yogyakarta: Kreasi Wacana

Santoso, S. 1984. Konsep Struktur dan Bentuk Kota Jawa s/d Abad ke 18. dalam majalah I.B.T. Locale-Techniek 5 (1936) No. 3, Hal. 59

Shohibuddin, 2003. Artikulasi Kearifan Tradisional Dalam Pengelolaan Sumberdaya Alam Sebagai Proses Reproduksi Budaya. Tesis Sekolah Pasca Sarjana Institut Pertanian Bogor

Slamet, Yulius. 2006. Metode Penelitian Sosial. Surakarta: UNS Press

Soelaiman, Munandar. 1998. Dinamika Masyarakat Transisi. Yogyakarta: Pustaka Pelajar

Susanto, Astrid. 1999. Pengantar Sosiologi dan Perubahan Sosial. Jakarta: Putra Abadia

Suhastharja, RM AP.1984. Analisa Bentuk Karawitan. Yogyakarta: ASTI

Sutopo,H. B.2002. Metodologi Penelitian Kualitatif. Surakarta: Sebelas Maret University Press

Sutrisno, Mudji Ed. 2005. Teori-Teori Kebudayaan. Yogyakarta: Penerbit Kanisius

Yin, Robert K. 1997. Studi Kasus Desain dan Metode. Jakarta: Rajagrafindo Persada

Yinger, J.Milton. Counterculture: The Promise And Peril Of A World Turned Upside Down. New York: The Free Press 